Article

\title{
The Influence of Tool Shape on Plastic Metal Flow, Microstructure and Properties of Friction Stir Welded 2024 Aluminum Alloy Joints
}

\author{
Yumeng Sun ${ }^{1}$, Wei Liu ${ }^{1, *}$, Yupeng $\mathrm{Li}^{1}{ }^{1}$, Wenbiao Gong ${ }^{1}{ }^{1}$ and Chuan $\mathrm{Ju}^{2}$ \\ 1 School of Materials Science and Engineering, Changchun University of Technology, Changchun 130012, China; \\ m18340806880@163.com (Y.S.); lyp.ccut@163.com (Y.L.); gwbiao@163.com (W.G.) \\ 2 CRRC NANJING PUZHEN Co., Ltd., Nanjing 210031, China; juchuan1120@163.com \\ * Correspondence: liuwei920107@sina.com; Tel.: +86-15699568380
}

check for

updates

Citation: Sun, Y.; Liu, W.; Li, Y.; Gong, W.; Ju, C. The Influence of Tool Shape on Plastic Metal Flow, Microstructure and Properties of Friction Stir Welded 2024 Aluminum Alloy Joints. Metals 2022, 12, 408. https://doi.org/10.3390/met12030408 Academic Editors: Yongxian Huang and Li Zhou

Received: 26 January 2022

Accepted: 23 February 2022

Published: 26 February 2022

Publisher's Note: MDPI stays neutral with regard to jurisdictional claims in published maps and institutional affiliations.

Copyright: (C) 2022 by the authors. Licensee MDPI, Basel, Switzerland. This article is an open access article distributed under the terms and conditions of the Creative Commons Attribution (CC BY) license (https:// creativecommons.org/licenses/by/ $4.0 /$ )

\begin{abstract}
In this paper, the effect of different shapes of tool pin on the plastic flow of 2024-T6 aluminum alloy during friction stir welding was studied. In order to observe the plastic flow of materials more clearly, we chose the method of friction stir welding of dissimilar materials, considering the different corrosive characteristics of aluminum alloys made of different materials when exposed to the same corrosive liquid. By studying and comparing the temperature field, macro and microstructure, microhardness and tensile properties of welded joints, the results indicated that the metal in the weld nugget zone (WNZ) mainly came from the base metal of the advancing side, the thread being the driving force of the downward movement of the FSW plastic metal. The deep groove thread tool pin had the strongest ability to drive the metal downward. The conical cam thread tool pin had the strongest stirring effect on materials and the best metal fluidity. The macroscopic morphology, microstructure, mechanical properties and fracture morphology of different joints were analyzed, and the results showed that all joints could form an excellent union, with an onion ring pattern appearing in cross-section. The minimum grain size of the WNZ formed by the conical cam thread stirring head was 7 12 $\mu \mathrm{m}$; the hardness was least at the junction of the heat affected zone (HAZ) and the thermo-mechanically affected zone (TMAZ). However, the hardness of the weld formed by the conical cam thread at this point was higher than that of other stirring heads; the tensile strength of all joints was more than $80 \%$ of the $\mathrm{BM}$, and the maximum tensile strength of the joint welded by the conical cam thread tool pin was $364.27 \mathrm{MPa}$, accounting for $86.73 \%$ of the base metal (BM). The elongation after break was $14.95 \%$. Tensile fracture morphology analysis showed that all joints were fractured by plastic fracture.
\end{abstract}

Keywords: friction stir welding; tool shape; metal flow; mechanical properties; grain size

\section{Introduction}

2024 aluminum alloy is an Al-Cu-Mg series hard aluminum alloy, which has been used in modern industry due to its excellent comprehensive mechanical properties and high temperature creep resistance [1-3]. Friction stir welding (FSW), as an emerging solid welding process, was invented by The Welding Institute (TWI) of the U.K. in 1991 [4-6]. Compared with traditional fusion welding methods, FSW overcomes welding defects, such as porosity and heat crack in the joint, and has high welding efficiency, no alloy element burning, small deformation and other advantages [7-9].

Studies [10] have shown that the main factors affecting the quality of weld joints in the FSW process include welding speed, rotation speed, shoulder pressure, and shape of the tool pin. In the process of FSW, the pin is an important factor affecting material flow. A reasonable structure design of the pin is conducive to better material flow and mixing in the FSW process, and achieves better performance of welded joints [11]. Many researchers have studied the effect of the tool pin on the microstructure and properties of FSW joints of aluminum alloys. Md.Reza-E-Rabby et al. [12] conducted FSW tests on the 6061-T651 
aluminum alloy using nine different shapes of pin (threaded pin and threaded pin with $1,2,3$, 4 flat; unthreaded pin and unthreaded pin with 1, 2, 4 flat). By comparing and studying the microstructure, torque, temperature and mechanical properties of welded joints, it was found that, under the same welding conditions, the joint formed by welding with the threaded pin was better, and that defects could not be eliminated irrespective of how many platforms the cylindrical tool had. For threaded pins, the number of flats on the threads will also affect the shape and performance of the welded joint. Du et al. [13] used two different shapes of tool pin to weld $16 \mathrm{~mm}$ thick 5083-H112 aluminum alloy sheet; the results showed that by changing the shapes of the tool pin, the degree of fragmentation of the oxide layer can be changed, while the severity of the ' $\mathrm{Z}$ ' line and the internal quality of the weld can be affected. In addition to research on the influence of the shape of the stirring needle on the FSW of the same material, research has also focused on different materials. M. Ilangoran et al. [14] studied the effect of different shapes of pin on the microstructure and mechanical properties of dissimilar materials using friction stir welds of $6 \mathrm{~mm} 6061$ and 5086 aluminum alloys. It was found that the welded joints produced using a cylindrical thread shape of pin produced better performance, because the welded joints under this condition had finer grains and onion rings, and there were fine even precipitates. Yang Zhou et al. [15] studied the effects of three different shapes of pin (i.e., quadrangular frustum pyramid, frustum, quadrangular prism) on the microstructure and properties of 6061-T6 aluminum alloy welded joints at high rotational speeds (11,000 rpm). The test results showed that better welding joints can be obtained when the quadrangular frustum pyramid shape pin is used. However, with respect to FSW of the 2 series aluminum alloy, there are still very few studies of the tool pin. Wang et al. [16] used four different shapes of tool pin to perform FSW on $4 \mathrm{~mm}$ thick 2024 aluminum alloy and analyzed the hardness and tensile strength of the joints. The results showed that the joint hardness curve was w-shaped, and, for the four types of joint elongation rate with tensile strength increase assessed, the joint performance of the triangular pyramid tool pin was the best. K. Ramanjaneyulu et al. [17] studied the effect of five different shapes of tool pin (i.e., conical, triangular, square, pentagon, hexagon cross-sections) on FSW joints of $5 \mathrm{~mm}$ 2014T6 aluminum alloy. Through comparison and analysis of the macro and microstructure, temperature field and mechanical properties of the welded joint, it was found that the shape of the pin had a greater influence on the thick plate, the more flats on the pin, the higher the peak temperature, the faster the temperature change rate, and the smaller the grain of the welded joint.

Although some researchers have studied the role and influence of the pin in the FSW process of aluminum alloy, there are still few studies on the effect of the pin on FSW joints of 2 series aluminum alloys. Previous research on the pin has been limited to the observation of macroscopic morphology, microstructure, and the comparison of mechanical properties and other features. According to previous research on friction stir welding of dissimilar aluminum alloys [18-20], it has been observed, from the microstructure, that different series of aluminum alloy have different corrosion resistance to the same corrosion solution, leading to different color of the microstructure. In contrast to previous studies, this investigation applied the welding method to dissimilar materials, using a dissimilar aluminum alloy exposed to the same corrosion liquid to evaluate different characteristics of corrosion resistance, studying the influence of different shapes of pin on the microstructure, mechanical properties and material plastic flow of FSW joints of the 2024-T6 aluminum alloy.

In this paper, the temperature field, macro and microstructure and mechanical properties were jointly considered to analyze the influence of different shapes of pin on $4 \mathrm{~mm}$ 2024-T6 aluminum alloy friction stir welding joints, not only to provide experimental data and theoretical analysis of FSW of 2 series aluminum alloy, but also to provide new ideas for research methods used to evaluate material plastic flow. 


\section{Materials and Methods}

In this experiment, the experimental material was 2024 aluminum alloy plate under T6 condition with a thickness of $4 \mathrm{~mm}$. The dimension of the workpiece was $300 \mathrm{~mm} \times 100 \mathrm{~mm}$ $(\mathrm{L} \times \mathrm{W})$. Figure 1 shows an image of the FSW setup. The chemical compositions of 2024-T6 aluminum alloy and 6061-T6 aluminum alloy are shown in Tables 1 and 2, respectively. The ultimate tensile strength and elongation of 2024-T6 aluminum alloy after fracture were $420 \mathrm{MPa}$ and $23 \%$, respectively. The ultimate tensile strength and elongation of 6061 aluminum alloy after fracture were $308 \mathrm{MPa}$ and $14 \%$, respectively. The material of the pin was W6Mo5Cr4V2 high-speed tool steel. The shape of pins used in this study are shown in Figure 2a (respectively, conical thread (A), deep groove thread (B), and conical cam thread (C)). Figure $2 \mathrm{~b}-\mathrm{d}$ shows the shape of the tool pin more clearly. Figure $2 \mathrm{~b}$ shows the common thread shape of the pin; the thread on the tool pin B was deepened on this basis as shown in Figure 2c. Figure 2d shows the shape of the conical cam thread. The diameter of the tool pin $A$ at the root and end were $7 \mathrm{~mm}$ and $5 \mathrm{~mm}$. The tool pin B had three deep grooves with a rotation angle of $120^{\circ}$ with respect to tool pin A. Tool pin C was machined with three $120^{\circ}$ platforms on the surface of tool pin A. The length of the tool pin was $3.7 \mathrm{~mm}$. The shoulder of all the tool pins referred to above were concentric circles with a diameter of 18 $\mathrm{mm}$. The friction stir welding machine used in the experiment was FSW-LM-AL16-2D. The rotational speed was $1000 \mathrm{rpm}$ and the welding speed was $500 \mathrm{~mm} / \mathrm{min}$. The tilting angle of the tool was $2.5^{\circ}$.

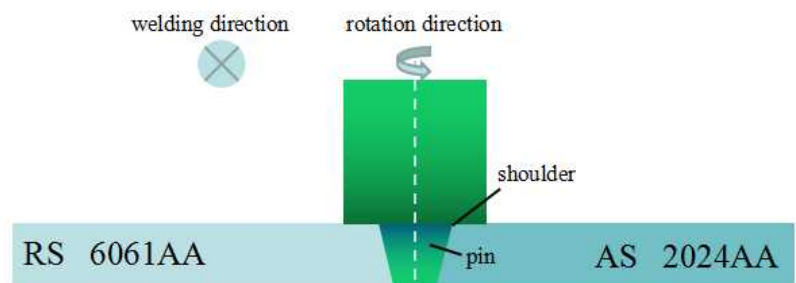

Figure 1. Image of the FSW setup.

Table 1. Chemical composition of 2024 aluminum alloy (mass fraction/\%).

\begin{tabular}{ccccccc}
\hline $\mathbf{C u}$ & $\mathbf{M g}$ & $\mathbf{M n}$ & $\mathbf{F e}$ & $\mathbf{S i}$ & $\mathbf{Z n}$ & Al \\
\hline $3.8 \sim 4.8$ & $1.2 \sim 1.8$ & $0.3 \sim 0.9$ & $\leq 0.5$ & $\leq 0.5$ & $\leq 0.3$ & Bal. \\
\hline
\end{tabular}
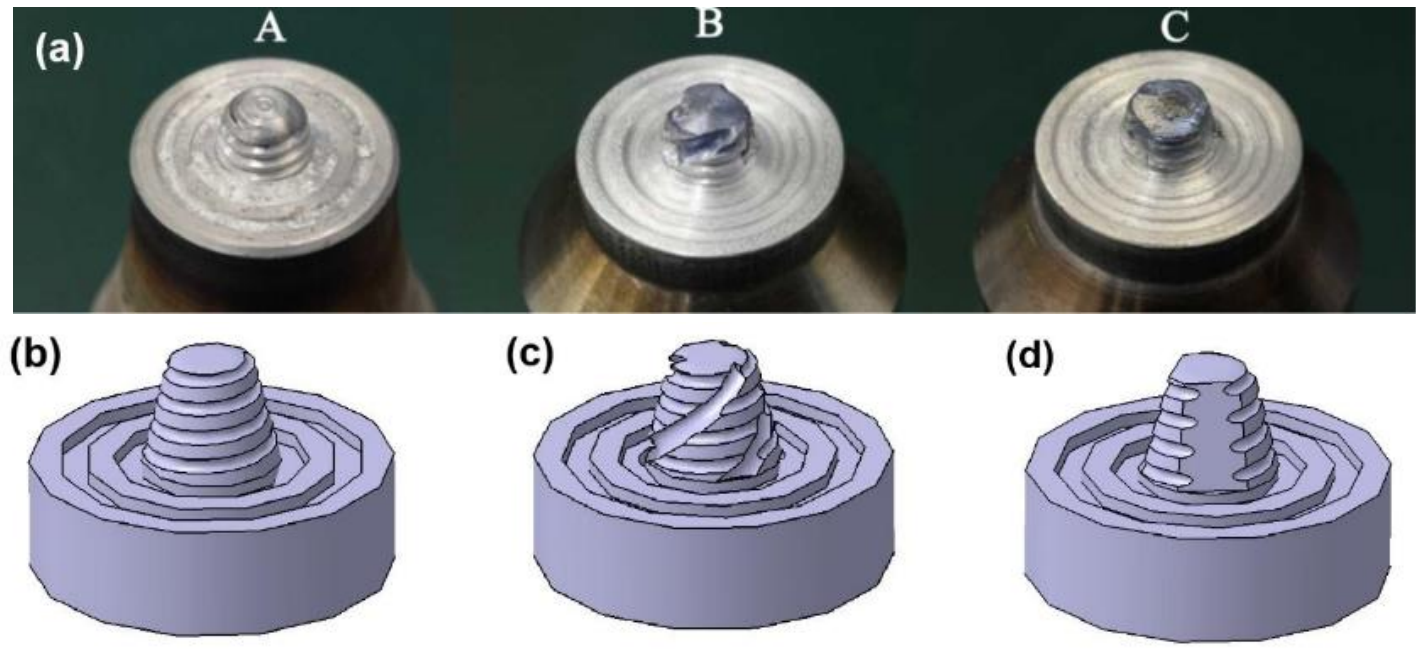

Figure 2. Geometries of three kinds of tool pins: (a) actual shapes of pins, (b) conical thread, (c) conical cam thread. 
Table 2. Chemical composition of 6061 aluminum alloy (mass fraction/\%).

\begin{tabular}{ccccccccc}
\hline $\mathbf{C u}$ & $\mathbf{M g}$ & $\mathbf{M n}$ & $\mathbf{F e}$ & $\mathbf{S i}$ & $\mathbf{Z n}$ & $\mathbf{C r}$ & $\mathbf{T i}$ & $\mathbf{A l}$ \\
\hline $0.15 \sim 0.4$ & $0.8 \sim 1.2$ & 0.15 & 0.7 & $0.4 \sim 0.8$ & 0.25 & $0.04 \sim 0.35$ & 0.15 & Bal. \\
\hline
\end{tabular}

During the welding process, a k-type temperature thermocouple was used to measure the temperature evolutions at different distances from the advancing side (AS) and the retreating side (RS) to the weld center. The location of the temperature measurement point is shown in Figure 3. After welding, the metallographic samples were prepared on the welded parts without defects, and the polished surface was etched by $15 \% \mathrm{NaOH}$. A Nikon EPIPHOT 300 was used to observe the microstructure of the joints. EBSD images were used to analyze the size of the microcrystalline and grain boundary orientation in the welded nucleus. Tensile specimens were cut according to GB/T228.1-2010 standards, and wire electrical discharge machining was used for cutting according to the schematic diagram shown in Figure 4. In order to ensure the accuracy of data, we stretched three samples for each group of parameters and calculated the average value as the final result. A hardness test was carried out in the middle of the weld cross-section using a WDW-200 microhardness tester. According to the preparation process of the metallographic sample, the sample was polished and slightly corroded. The flow of the plastic metal was observed and photographed by the metallographic microscope.

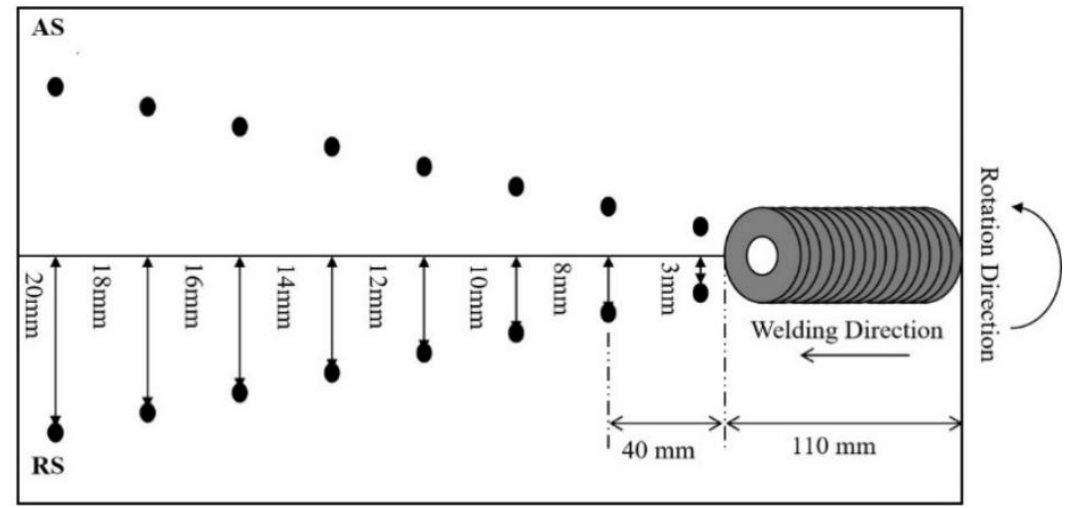

Figure 3. Distribution of temperature measurement points.

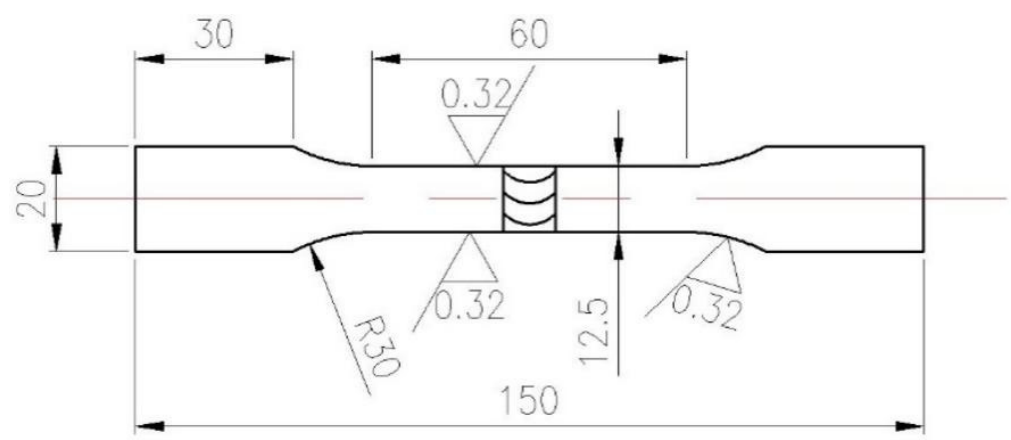

Figure 4. Dimensions of tensile specimen.

\section{Results and Discussion}

\subsection{Temperature Field}

Figure 5 shows the welding thermal cycle curves of the three different shapes of tool pin on the AS and RS at different positions of the weld. The welding thermal cycle curves of the welded joint when using three different shape of tool pins generally show similar trends. This is because the contact area and compressive stress between the shoulder and the workpiece are larger than that of the tool pin. The heat generated by the shoulder is 
the main heat source during the FSW process. The dimensions of the shoulder of the three different shape of tool pins are the same, so in the welding process, the heat production of the three different shapes of the pin is not much different, although their shapes are different. In addition, as we can see from Figure 5, the peak temperatures on the AS and RS of the joint when using the tool pin A at a distance of $3 \mathrm{~mm}$ from the center of the weld were $423^{\circ} \mathrm{C}$ and $408.6^{\circ} \mathrm{C}$. The peak temperatures on the AS and RS of the joint when using tool pin B at a distance of $3 \mathrm{~mm}$ from the weld center were $398^{\circ} \mathrm{C}$ and $377^{\circ} \mathrm{C}$. The peak temperatures on the AS and RS of the joint when using tool pin $\mathrm{C}$ at a distance of $3 \mathrm{~mm}$ from the weld center were $368.7^{\circ} \mathrm{C}$ and $345.1^{\circ} \mathrm{C}$. The slight temperature difference at this position is mainly caused by the tool pin shape. The relationship between the contact surface area of the three different pins and the workpiece was A $>$ B $>C$. Under the same welding parameters, the heat input in the welding process is directly proportional to the friction area, so the heat generated when using tool pin A was the highest, and for tool pin C was the lowest. We also found that the peak temperature of the measured point on the AS was slightly higher than that of the RS, irrespective of the shape of pin used, and the temperature difference was about $15 \sim 30^{\circ} \mathrm{C}$. This result is consistent with [21], mainly because the flow direction of the metal on the AS is the same as the welding direction during the FSW process, and the flow direction on the RS is opposite to the welding direction. The strain rate of the metal on the AS was greater than that of the RS; the metal on the AS was stirred more vigorously in the same time than was the case for RS, so the peak temperature of the AS was higher.
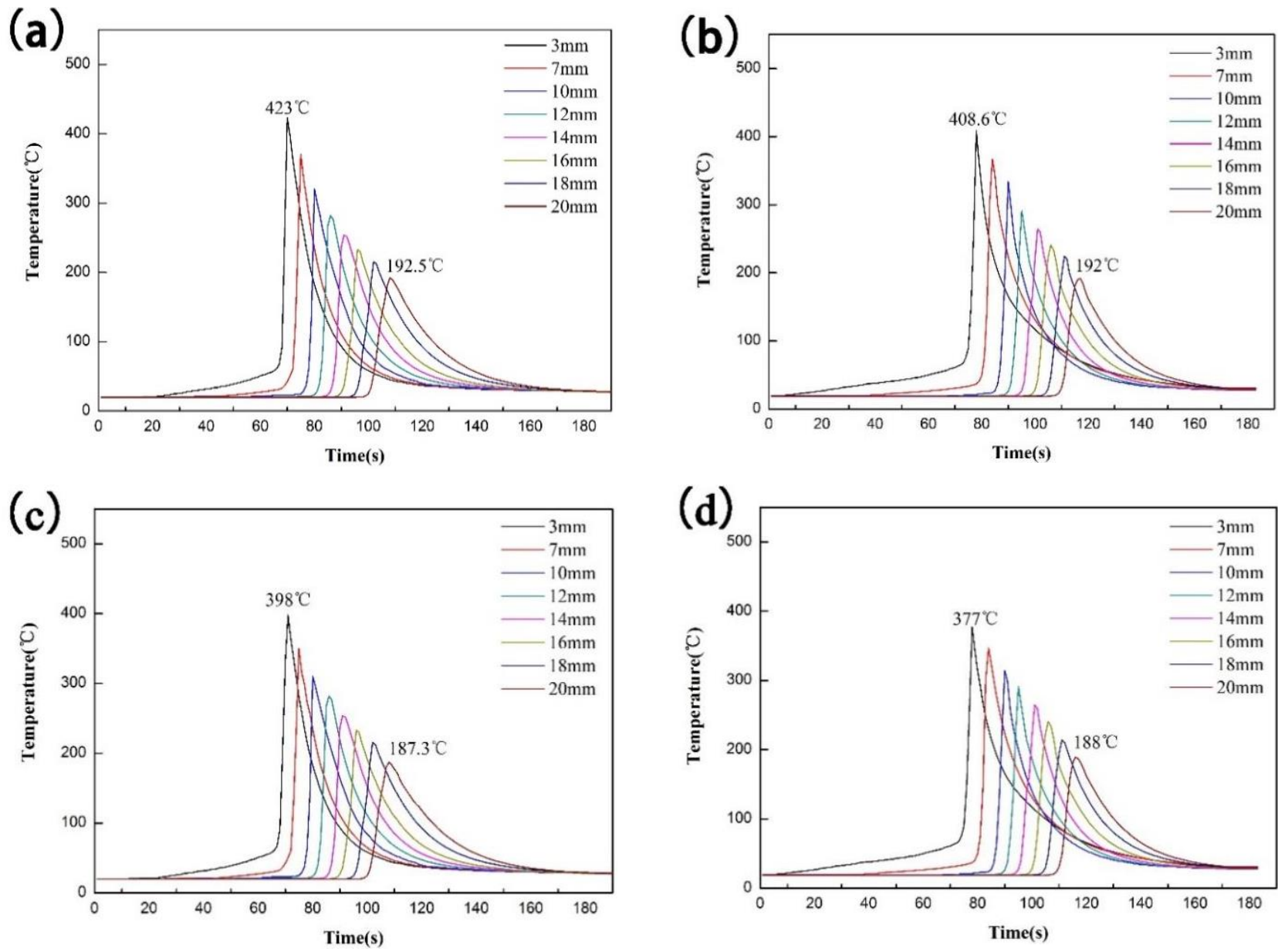

Figure 5. Cont. 

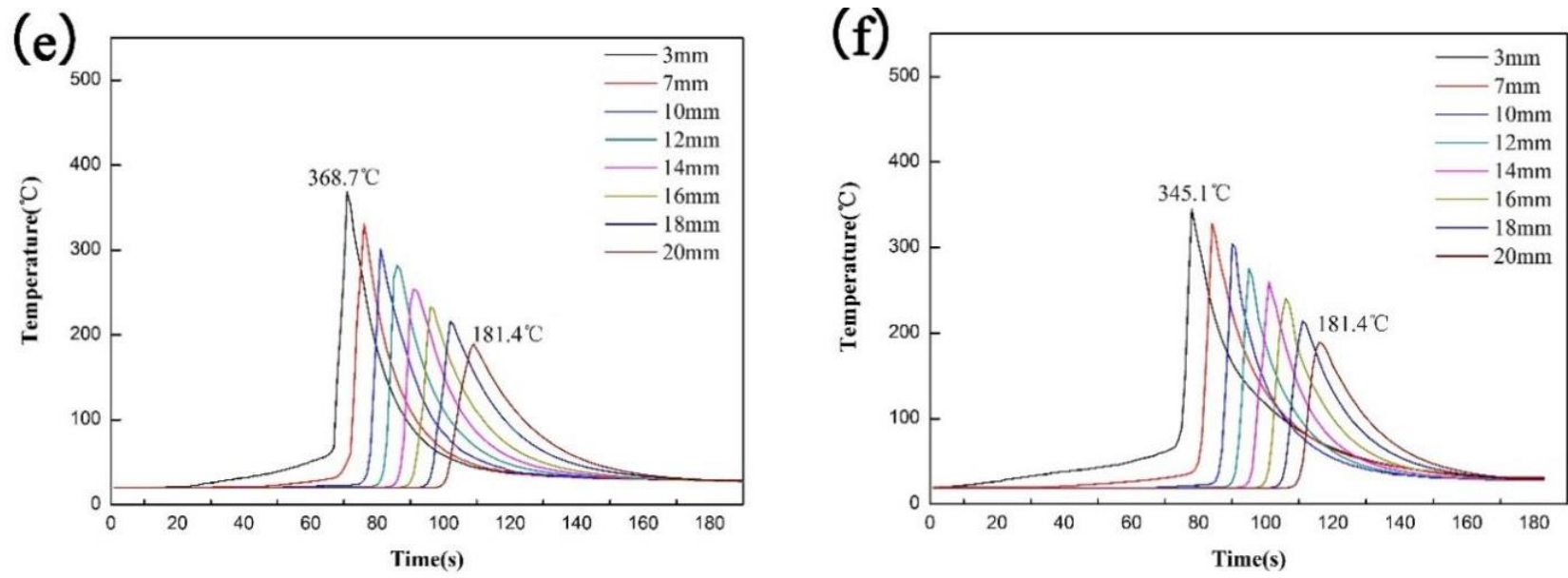

Figure 5. Welding thermal cycle curves of different tool pins. (a) AS of tool pin A; (b) RS of tool pin A; (c) AS of tool pin B; (d) RS of tool pin B; (e) AS of tool pin C; (f) RS of tool pin C.

\subsection{Metal Migration of Weld Cross-Section}

Figure 6 shows the macroscopic characteristics of the weld cross-sections obtained using three different shapes of tool pin. We divided the macroscopic image of the welded joint into four areas: shoulder affect zone (SAZ), turbulent zone, TMAZ-AS and TMAZ-RS. The AS material was 2024-T6 Al alloy of light color and the RS material was $6061 \mathrm{Al}$ alloy of dark color. The plasticized metal on the AS is directly affected by the tool pin, and the plasticized metal rotates with the tool pin and makes a 'vortex' motion on the same layer. Because the 'vortex metal' interacts with a small amount of plasticized metal when it rotates through the RS, part of the metal precipitates on the RS or flows back through the RS, and most of the metal finally stays on the AS, which causes the phenomenon that the metal on the AS is more than that of the RS in the weld joint. At the same time, part of the metal migrates downwards under the action of the driving force generated by the counterclockwise rotation of the right-hand thread. The amount of the metal on the lower layer continues to accumulate and is restricted by the rigid backing plate at the bottom, and then expands laterally to both sides, thus causing the 'onion ring' to have a small top and a big bottom. According to Ke Liming's theory [22], a large number of plasticized metals migrate downward during the stirring process, and a circular extrusion zone is generated for the surrounding metals. 'Onion rings' are formed by metallurgical mixing on the side and rear of the tool pin. Therefore, the height of 'onion ring' formation can be used to characterize the downward migration ability of weld metal. The heights of the 'onion ring' (" $\mathrm{H}$ " in Figure 6) from the bottom of the weld welded by the three tool pins were $2.54 \mathrm{~mm}$, $1.77 \mathrm{~mm}$ and $2.31 \mathrm{~mm}$. Three deep grooves were added to tool pin B on the basis of tool pin $\mathrm{A}$, which improved the ability for downward metal migration, and the 'onion ring' position was the lowest. Tool pin C was cut into an inscribed triangle on the basis of tool pin A, and its volume was reduced, but its stirring effect on the material was not weakened. On the contrary, it showed a smaller hindrance to the flow of the material and the metal could better migrate downwards.

The metal below the weld is squeezed by the metal in the WNZ and cannot expand to the lower layer, so, part of the lower layer metal moves upward from the far side of the tool pin (TMAZ) bypassing the WNZ. The metal in the RS enters above the WNZ and mixes violently with the AS metal, creating a 'turbulent zone'. The shape of the 'turbulent zone' is related to the strength of the metal flow in the weld. When its fluidity is strong, the turbulent zone overlaps like fish scales, as shown in Figure 6c. Tool pin $C$ had the effect of edge cutting on the basis of tool pin A, which enhanced the stirring effect of the material. At the same time, the excised part reduced the obstruction to the movement of the material, which enhanced the fluidity of the plastic metal. When the fluidity is moderate, a hook like occlusal structure is formed, as shown in Figure 6b. This is because tool pin B had three 
more deep grooves with a rotation angle of $120^{\circ}$ based of tool pin $\mathrm{A}$, which reduced the obstruction to the material movement.
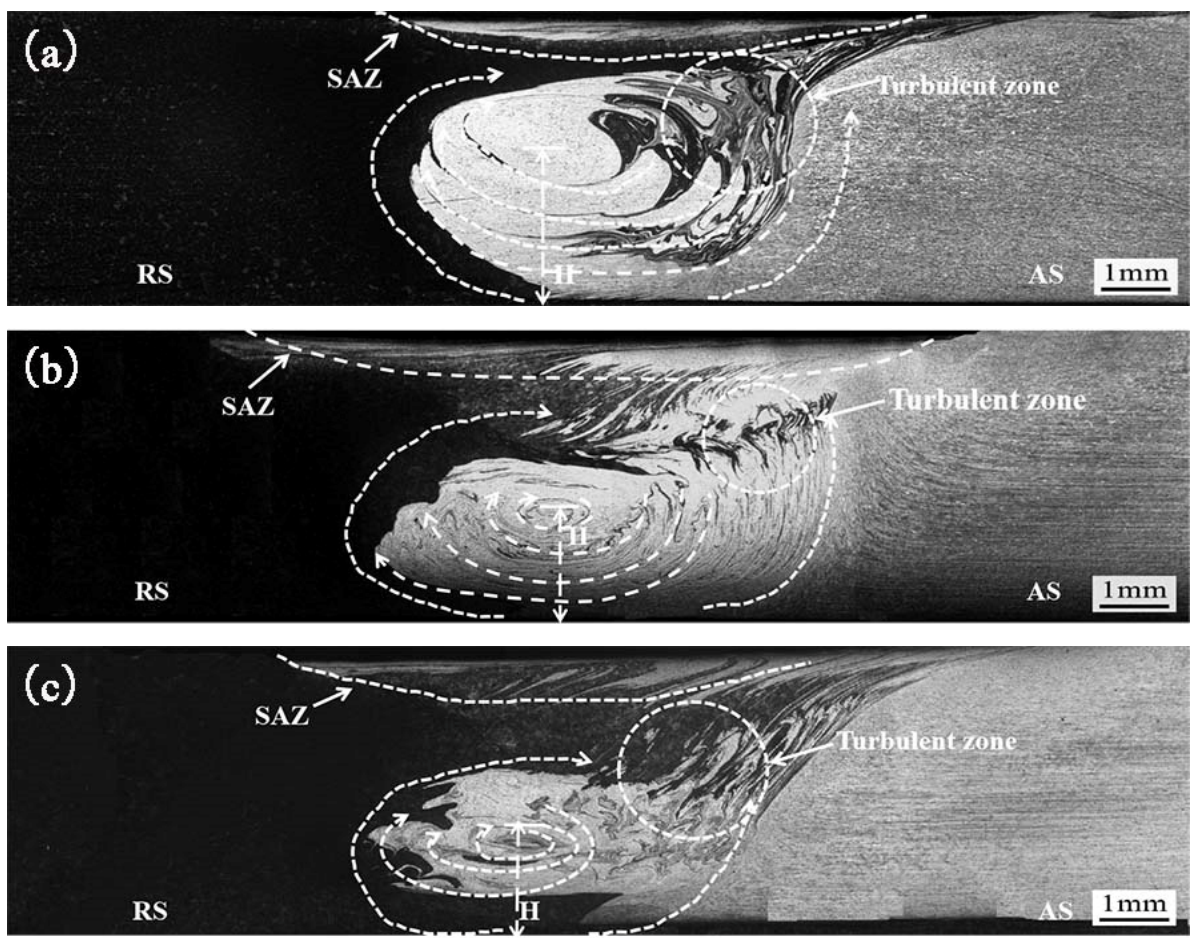

Figure 6. Macroscopic characteristics of weld cross-section flow obtained using three tool pins. (a) tool pin A; (b) tool pin B; (c) tool pin C.

\subsection{Macroscopic Morphology of Welds}

The macroscopic morphology of the FSW joint can be divided into weld nugget zone (WNZ), shoulder affected zone (SAZ), heat affected zone (HAZ), thermo-mechanically affected zone (TMAZ), and shoulder-affected zone (SAZ) in five parts [23]. The 'onion ring' pattern is caused by the fact that when the tool pin moves along the welding direction, the plasticized metal is pushed back to RS, forming semi-ellipsoid area superposition to form continuous weld seams. Cross-sectional images of the weld zone welded by different shapes of pin are shown in Figure 7. We can see that the welds are well formed without holes, tunnels or other defects. In addition, the cross-sectional morphology of the weld is obviously different under the action of different shape of tool pins.

The cross-section of the weld formed by tool pin A is shown in Figure 7a. The stir of the material mainly depends on the friction and extrusion effect of the tool pin, and the morphology of the 'onion ring' is formed in the middle of the WNZ. The cross-section of the weld formed by tool pin B is shown in Figure $7 \mathrm{~b}$. Tool pin B has three deep grooves with a rotation angle of $120^{\circ}$ on the basis of tool pin A. The stirring effect of tool pin B on plasticized metal was enhanced compared to tool pin A, so the fluidity of the metal was improved. At the same time, due to the presence of deep grooves, plasticized metals migrate downward more easily, and the 'onion ring pattern' is located below the WNZ. The cross-section of the weld formed by tool pin $C$ is shown in Figure 7c. On the basis of tool pin $A$, tool pin $C$ has the feature of a 'cut edge', which strengthens the stirring effect of the plasticized metal, making the flow of plasticized material more sufficient, and produces a complete and obvious 'onion ring'. It can be seen from Figure 7 that, from Figure $7 \mathrm{a}-\mathrm{c}$, the boundary between the WNZ and the TMAZ becomes increasingly blurred, and the scope of the TMAZ becomes larger and larger. Tool pin A has the largest contact area with the material, so friction generates the most heat; at the same time, the poor stirring effect on the material concentrates the heat. The contact area between the tool pin $B$, tool pin $C$ and the material gradually decreases, and the friction heat generation decreases. In addition, the 
stirring effect of the material is enhanced, and the heat is more dispersed, so the boundary between the WNZ and the TMAZ becomes blurred.
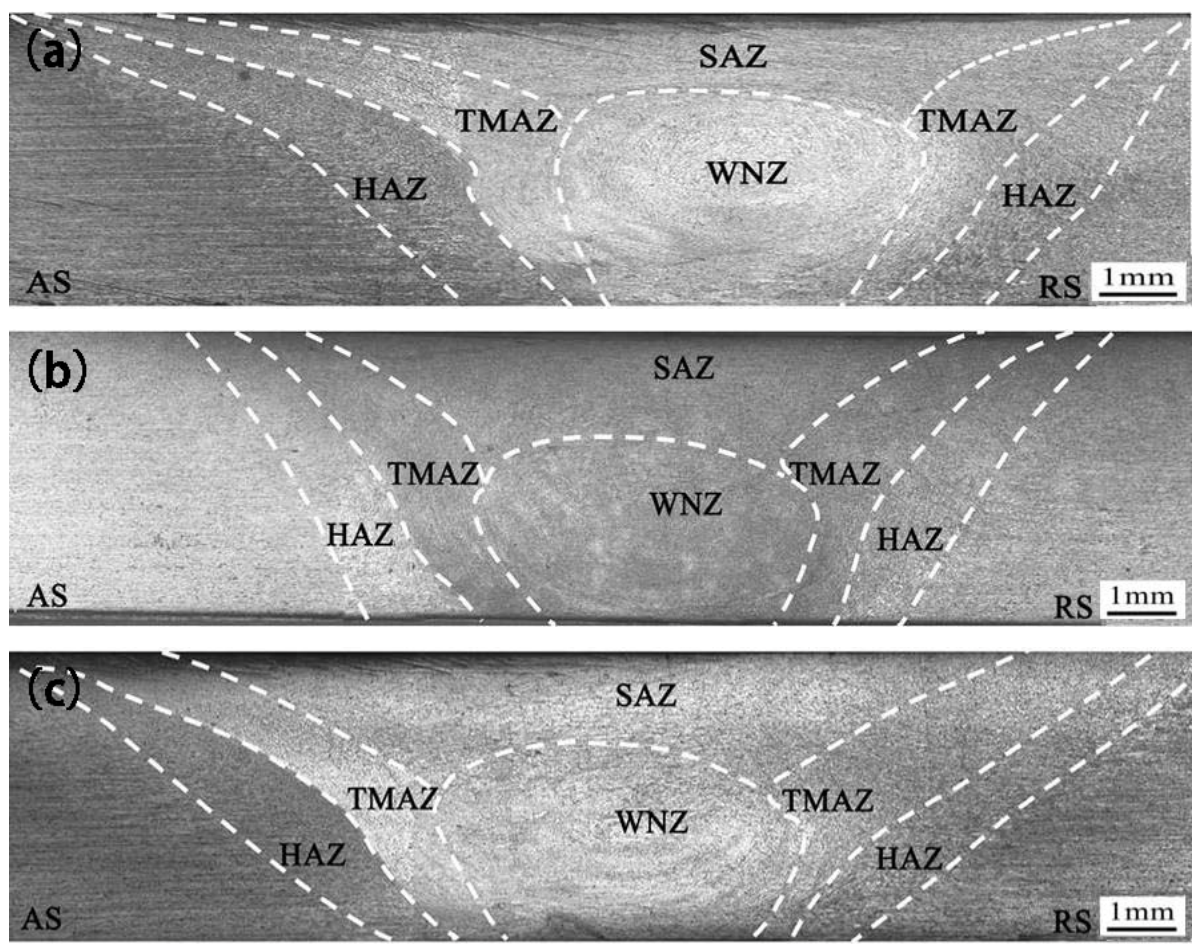

Figure 7. Cross-sectional images of weld zone fabricated with different tool pin profiles. (a) tool pin A; (b) tool pin B; (c) tool pin C.

\subsection{Microstructure of Welds}

The EBSD images of the WNZ welded by different tool pins are shown in Figure 8. This region experiences a high temperature cycle and dynamic recrystallization due to the strong agitation of the tool pin. The grains in the BM change the original strip structure to a fine equiaxed recrystallization structure. Figure $8 \mathrm{a}$ is the EBSD image of the WNZ formed by the tool pin $\mathrm{A}$, the average grain size is about $12 \sim 18 \mu \mathrm{m}$. Figure $8 \mathrm{~b}$ is the EBSD image of the WNZ formed by the tool pin B, the average grain size is about $8 \sim 14 \mu \mathrm{m}$. Figure $8 \mathrm{c}$ shows the EBSD image of the WNZ formed by the tool pin $C$, the average grain size is about 7 12 $\mu \mathrm{m}$. From Figure 8a,c,e, the grain size of the WNZ gradually becomes smaller, and the grain boundary is gradually blurred. According to the Zener-Hollomon equation [19], when the welding parameters are the same, the dynamic recrystallization of the WNZ to form equiaxed crystal grain size is mainly affected by the welding peak temperature $\mathrm{T}(\mathrm{K})$ and the strain rate (/s) (the higher the $\mathrm{Z}$ value, the smaller the grain size). At the same time, due to the increase in the peak temperature, the weld metal stays at a high temperature for a longer time, which will produce coarse recrystallized grains and the grains will grow.

From Figure $8 \mathrm{~d}-\mathrm{f}$, it can be seen that the large-angle grain boundaries $\left(5^{\circ} \sim 180^{\circ}\right)$ in the WNZ of the three different shapes of tool pin accounted for $76.4 \%, 75.5 \%$ and $74.7 \%$, respectively, which is significantly higher than the proportion of small-angle grain boundaries $\left(2^{\circ} \sim 5^{\circ}\right)$. According to [20], the dislocations generated by the severe plastic deformation in the WNZ are absorbed by the subgrain boundaries, which increases the orientation difference of the low-angle grain boundaries, resulting in the subsequent dynamic recrystallization process. The low-angle grain boundaries easily become highangle grain boundaries, and then form fine equiaxed crystals. The gradual decrease in the proportion of high-angle grain boundaries in the WNZ indicates that the degree of dynamic recrystallization has decreased. 

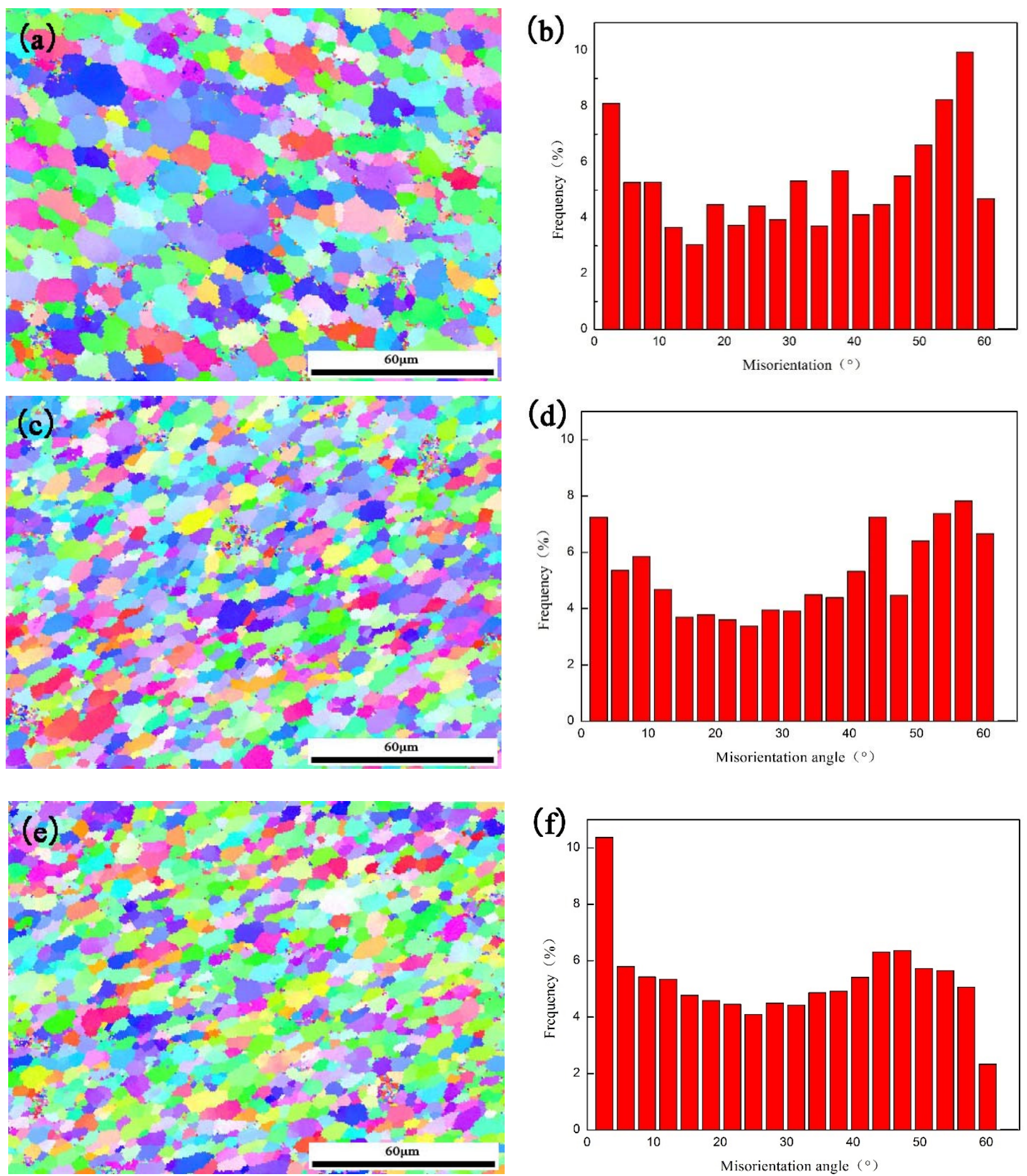

Figure 8. EBSD images and grain boundary orientation and angle distribution maps in WNZ. (a) tool pin $\mathrm{A}$; (c) tool pin B; (e) tool pin C and corresponding grain boundary orientation angle distributions $(\mathbf{b}, \mathbf{d}, \mathbf{f})$.

\subsection{Micro-Hardness of Joints}

The hardness curves of the cross-section of the joint formed by the three tool pins are shown in Figure 9, and the average values of microhardness in different areas of welded joints with different shapes of pin are shown in Table 3. Firstly, looking at the overall trend, regardless of the shape of the pin, the microhardness trend exhibits a " $\mathrm{W}$ " shape. The hardness of the TMAZ and HAZ is relatively low. The lowest hardness occurs at the junction of the HAZ and TMAZ on the forward side. Combined with the previous temperature measurement results, this is because the welding temperature of the AS was 
higher, and, compared with the grain of the RS, the grains in the TMAZ and HAZ were exposed to higher temperature and grew into coarser grains. According to the Hell-Petch relationship, the larger the grain, the lower the hardness. The microstructure of WNZ underwent a welding head cycle at a higher temperature during welding. At the same time, violent plastic deformation occurred under the action of the tool pin, so the structure was of recrystallized grain. The recrystallization grain is very fine with high hardness, but slightly below the BM. This is consistent with the strength of the joint being lower than the BM. Under the action of heat and force, rough and regenerated deformed grains are produced in the TMAZ. The HAZ is only affected by the welding head cycle and the grain size is large. At the same time, some of the strengthened phase is dissolved in the aluminum matrix under the action of heat, and the hardness is low.

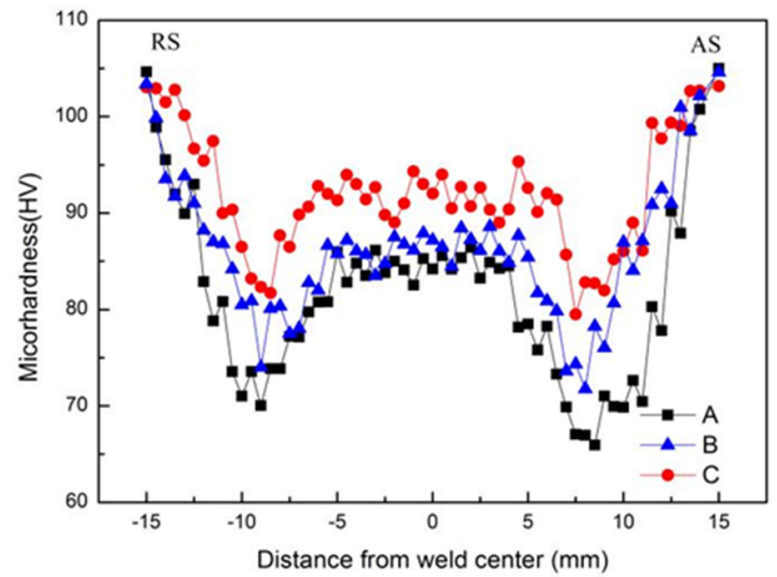

Figure 9. Micro-hardness of joints obtained by different tool pin profiles.

Table 3. Average microhardness values of different areas of welded joints of three different shapes of pin (HV).

\begin{tabular}{cccccc}
\hline Pin & HAZ (RS) & TMAZ (RS) & WNZ & TMAZ (AS) & HAZ (AS) \\
\hline A & 74.2 & 69.9 & 83.6 & 65.8 & 69.3 \\
B & 79.8 & 74.1 & 86.9 & 72.3 & 76.1 \\
C & 84.2 & 82.1 & 93.4 & 78.1 & 86.9 \\
\hline
\end{tabular}

Secondly, compared with tool pin A and tool pin B, the hardness of the joint formed by tool pin $C$ was improved, and the lowest hardness was $78.1 \mathrm{HV}$. This can also be combined with the previous temperature test results. Tool pin $C$ had the smallest surface area in contact with the workpiece, so generated less heat and showed a lower welding temperature, which reflects a larger hardness value for microhardness.

\subsection{Mechanical Properties of the Joint}

Figure 10 shows the fracture position of tensile specimens welded by three shapes of pin. All specimens fractured at TMAZ on the AS, with obvious $45^{\circ}$ fracture, smooth surface and gray fiber shape. This is because, in the welding process, the grains near the TMAZ are affected by the thermal cycle, and the precipitation phase is heated and precipitated. At the same time, this area was subjected to a small mechanical stirring effect, so the precipitated phase could not be broken to make it more evenly distributed, and the precipitated phase was segregated and aggregated, resulting in the mechanical properties of this part decreasing. At the same time, due to the characteristics of FSW, the cross-section of the weld was V-shaped, and the weak area of the joint was also V-shaped, resulting in $45^{\circ}$ cracking in the tensile process. 

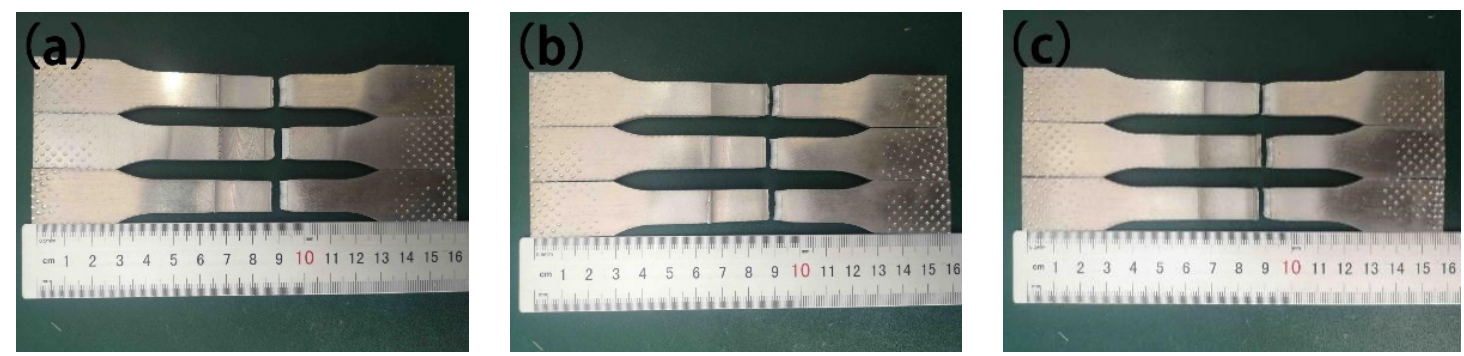

Figure 10. Fracture location diagram of tensile specimens of welded joints with different shapes of pin. (a) tool A (b) tool B (c) tool C.

Table 4 shows the tensile properties of 2024 aluminum alloy joints welded with different shapes of tool pins. It can be seen that the strength of the welded joints of the three tool pins was above $80 \%$ of the BM. The maximum strength of the weld joint when using tool pin $\mathrm{C}$ was $364.87 \mathrm{MPa}$, up to $86.73 \%$ of the $\mathrm{BM}$. The lowest strength of the weld joint when using tool pin A was $80.44 \%$ of the BM. It can be seen from the above test results that the tensile strength of the welded joint obtained under the welding condition of tool pin $C$ was the highest. This is because, from tool $A$ to tool $C$, the surface area of the pin in contact with the workpiece gradually decreased, and the heat generated by metal friction in the welding process gradually decreased, which led to temperature decreases in the TMAZ affected by the welding thermal, making the second phase particles in the joint less dissolved. It is well known that the more dissolved particles are in the second phase, the weaker the strength of the joint. Correspondingly, the less dissolved particles of the second phase are, the stronger the strength of the joint.

Table 4. Results of tensile test of joints welded by different tool pin profiles.

\begin{tabular}{ccccccc}
\hline Number & TS (MPa) & $\begin{array}{c}\text { Average } \\
\mathbf{( M P a )}\end{array}$ & JE (\%) & Elongation (\%) & Average (\%) & $\begin{array}{c}\text { Fracture } \\
\text { Location }\end{array}$ \\
\hline A1 & 325.69 & & & 9.95 & & AS TMAZ \\
A2 & 347.08 & 337.85 & 80.44 & 11.2 & 11.07 & AS TMAZ \\
A3 & 340.78 & & & 12.06 & & AS TMAZ \\
B1 & 340.82 & & & 12.64 & & AS TMAZ \\
B2 & 344.73 & 349.10 & 83.12 & 12.48 & 13.13 & AS TMAZ \\
B3 & 361.75 & & & 14.27 & & AS TMAZ \\
C1 & 359.92 & & & 14.91 & & AS TMAZ \\
C2 & 362.31 & 364.27 & 86.73 & 15.23 & 14.95 & AS TMAZ \\
C3 & 370.58 & & & 14.71 & & AS TMAZ \\
\hline TS- tensile strength, JE-joint efficiency.
\end{tabular}

\subsection{Fracture Morphology of the Joint}

Observing the fracture morphology of the joints formed by the tool pins of different shape, it was found that the fracture positions of all joints were located at the TMAZ on the AS. Figure 11 shows the fracture morphology of the welding joints, from which it can be seen see that there are different sizes of dimples, and the walls of the dimples are smooth, which is a typical plastic fracture. At the bottom of each dimple, there is a second-phase particle. The second-phase particles of larger particles form a larger dimple, and the very fine, dispersed second-phase particles form an isometric small dimple. Since the second-phase particles and the matrix have different bonding strengths, it is easy to form a crack core along the boundary of the second-phase particles during plasticization. Under the effect of stress, the crack core gradually grows, and as the plastic deformation increases, the connection area gradually thins until final fracture. Figure $11 \mathrm{a}-\mathrm{c}$ shows the fracture morphology of the joints formed by the welding of the three tool pins, all of which are equiaxed dimples, and the depth of the dimples also gradually increases, which is consistent with increase in elongation after fracture. 

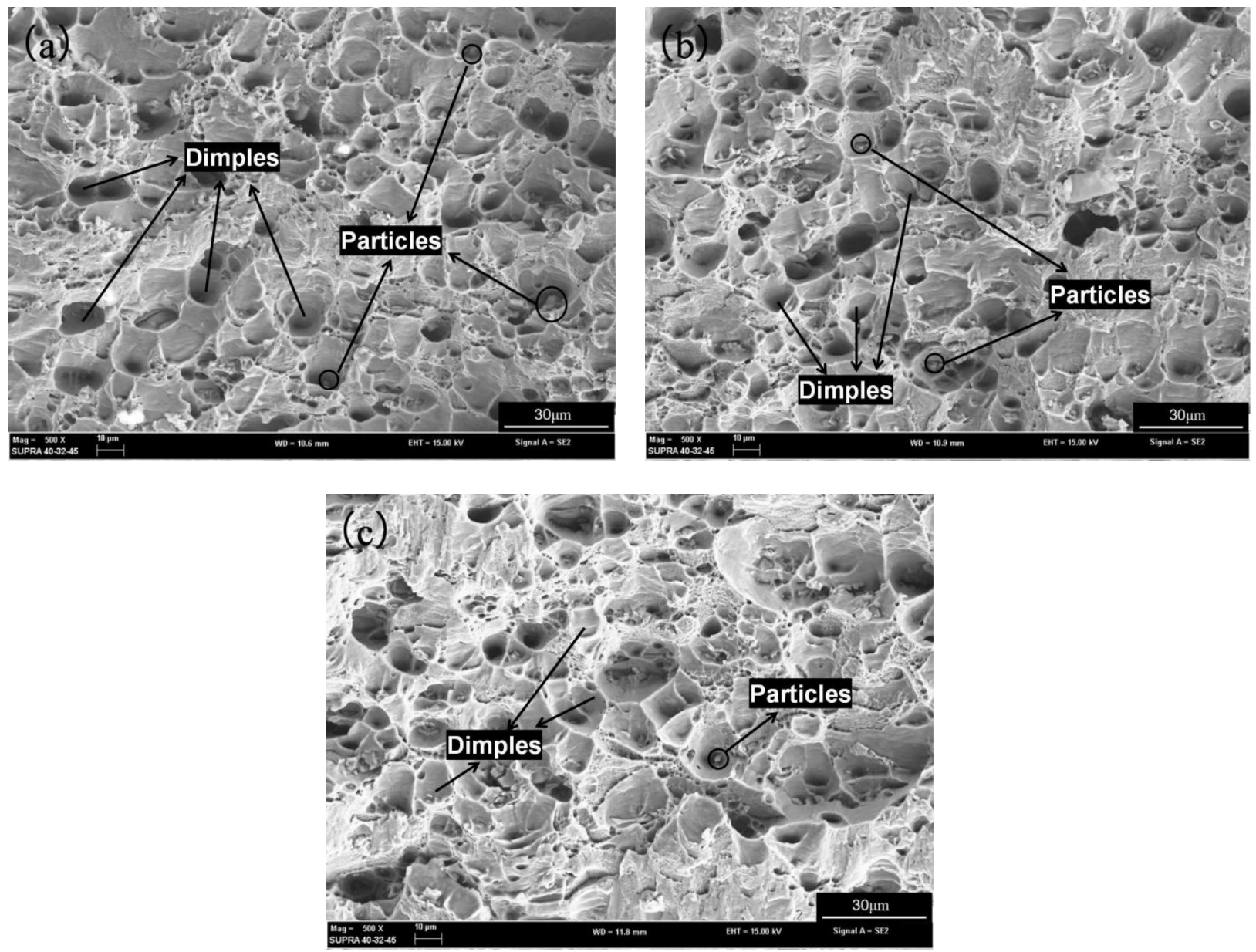

Figure 11. Fracture morphology of FSW joints. (a) tool pin A; (b) tool pin B; (c) tool pin C.

\section{Conclusions}

This paper investigated the influence of tool shape on plastic metal flow, microstructure and properties of friction stir welded 2024 aluminum alloy joints. The conclusions are summarized below:

1. The temperature at the edge of weld has a linear relationship with the distance from the measuring point to the heat source (weld). The temperature peak of the joint welded by three different pins is related to the contact surface area of the workpiece.

2. The metal in WNZ mainly comes from the base metal of advancing side. The thread is the driving force of the downward movement of FSW plastic metal. Tool pin B had the strongest ability to drive the metal downward. Tool pin $\mathrm{C}$ had the strongest stirring effect on metal and the smallest volume, the obstruction to metal was the least, and the fluidity of metal was the best.

3. The average grain size of the WNZ under three different tool pins (tool A, B and C) was 12 18 $\mu \mathrm{m}, 8 \sim 14 \mu \mathrm{m}, 7 \sim 12 \mu \mathrm{m}$, respectively The average grain size was mainly affected by the welding peak temperature: the higher the peak temperature, the larger the grain size.

4. The maximum strength of the weld joint when using the conical cam thread tool was $364.87 \mathrm{MPa}$, up to $86.73 \%$ of the BM. The lowest strength of the weld joint was 337.85 MPa when using the conical thread tool. The fracture forms of joint were plastic fracture. The joints welded by the conical cam thread tool showed the best performance. 


\begin{abstract}
Author Contributions: Conceptualization, methodology, resources, project administration, W.G. and W.L.; software, validation, supervision, Y.L.; formal analysis, investigation, writing-original draft preparation, visualization, C.J.; data curation, writing-review and editing, Y.S. All authors have read and agreed to the published version of the manuscript.

Funding: Jilin Province Development and Reform Commission industrial technology research and development project (Grant number: 2019C046-7) Changchun science and technology innovation “Double Ten" project (Grant number: 17ss024).
\end{abstract}

Institutional Review Board Statement: Not applicable.

Informed Consent Statement: Not applicable.

Data Availability Statement: Not applicable.

Conflicts of Interest: The authors declare no conflict of interest.

\title{
References
}

1. Sutton, M.A.; Reynolds, A.P.; Wang, D.Q.; Hubbard, C.R. A Study of Residual Stresses and Microstructure in 2024-T3 Aluminum Friction Stir Butt Welds. J. Eng. Mater. Technol. 2002, 124, 215-222. [CrossRef]

2. Li, J.Q.; Liu, H.J. Effects of tool rotation speed on microstructures and mechanical properties of AA2219-T6 welded by the external non-rotational shoulder assisted friction stir welding. Mater. Des. 2013, 43, 299-306. [CrossRef]

3. Pasebani, S.; Charit, I.; Mishra, R.S. Effect of tool rotation rate on constituent particles in a friction stir processed 2024Al alloy. Mater. Lett. 2015, 160, 64-67. [CrossRef]

4. Zhang, Z.H.; Li, W.Y.; Li, J.L.; Chao, Y.J. Effective predictions of ultimate tensile strength, peak temperature and grain size of friction stir welded AA2024 alloy joints. Int. J. Adv. Manuf. Technol. 2014, 73, 1213-1218. [CrossRef]

5. Li, W.F.; Li, J.F.; Zhang, Z.H. Metal Flow during Friction Stir Welding of 7075-T651 Aluminum Alloy. Exp. Mech. 2013, 53, 1573-1582. [CrossRef]

6. $\quad$ Rong, Z.Y.; Li, L.Q.; Chen, L.F.; Yuan, H.N.; Zhu, S.J.; Sun, Y.F.; Guan, S.K. The effect of Zn coating layer on the microstructure and mechanical properties of friction stir spot welded galvanized DP590 high-strength steel plates. Int. J. Adv. Manuf. Technol. 2021, 113, 1787-1798. [CrossRef]

7. Bozkurt, F.; Akir, F.H.; Schmidova, E.; Kumar, M. The effect of welding parameters on static and dynamic behaviors of spot welded ti6al4v sheets. J. Mater. Eng. Perform. 2020, 29, 7468-7479. [CrossRef]

8. Zeng, S.B.; Chen, G.; Dinaharan, I.; Liu, Q.; Shi, Q.Y. Microstructure and tensile strength of aa6082 t-joints by corner stationary shoulder friction stir welding: Effect of tool rotation speed. J. Mater. Eng. Perform. 2020, 29, 7094-7103. [CrossRef]

9. Zhang, H.J.; Wang, M.; Zhang, X.; Yang, G.X. Microstructural characteristics and mechanical properties of bobbin tool friction stir welded 2A14-T6 aluminum alloy. Mater. Des. 2015, 65, 559-566. [CrossRef]

10. Liu, F.; Liu, J.; Ji, Y.; Bai, Y. Microstructure, mechanical properties, and corrosion resistance of friction stir welded Mg-Al-Zn alloy thick plate joints. Weld. World 2021, 65, 229-241. [CrossRef]

11. Hoyos, E.; Serna, M.C. Basic Tool Design Guidelines for Friction Stir Welding of Aluminum Alloys. Metals 2021, 11, 2042. [CrossRef]

12. Reza-E-Rabby, M.; Tang, W.; Reynolds, A.P. Effects of thread interruptions on tool pins in friction stir welding of AA6061. Sci. Technol. Weld. Join. 2018, 23, 114-124. [CrossRef]

13. Du, J.L.; Cui, Z.M.; Yuan, Y.W.; Ma, D.S.; Ma, J.J.; He, C.S. The influence of needle shape on the quality of friction stir weld of 5083 aluminum alloy. Nonferrous MetPro 2017, 46, 26-30.

14. Ilangovan, M.; Boopathy, S.R.; Balasubramanian, V. Effect of tool pin profile on microstructure and tensile properties of friction stir welded dissimilar AA 6061-AA 5086 aluminium alloy joints. Def. Technol. 2015, 11, 174-184. [CrossRef]

15. Zhou, Y.; Chen, S.; Wang, J.; Wang, P.; Xia, J. Influences of Pin Shape on a High Rotation Speed Friction Stir Welding Joint of a 6061-T6 Aluminum Alloy Sheet. Metals 2018, 8, 987. [CrossRef]

16. Wang, S.J.; Ma, X.F.; Zhang, J.Y.; Che, W.B.; Wei, X.L. The effect of the shape of the mixing head on the mechanical properties of 2024 aluminum alloy FSW joints. Hot Work. Technol. 2017, 46, 47-50. (In Chinese)

17. Ramanjaneyulu, K.; Reddy, G.M.; Rao, A.V.; Markandeya, R. Structure-Property Correlation of AA2014 Friction Stir Welds: Role of Tool Pin Profile. J. Mater. Eng. Perform. 2013, 22, 2224-2240. [CrossRef]

18. Abd Elnabi, M.M.; Abdel-Mottaleb, M.M.; Osman, T.A.; El Mokadem, A. Influence of friction stir welding parameters on metallurgical and mechanical properties of dissimilar AA5454-AA7075 aluminum alloys. J. Mater. Res. Technol. 2019, 8, 1684-1693. [CrossRef]

19. Msomi, V.; Mbana, N.; Mabuwa, S. Microstructural analysis of the friction stir welded 1050-H14 and 5083-H111 aluminium alloys. Mater. Today 2019, 26, 189-192. [CrossRef]

20. Dewangan, S.K.; Tripathi, M.K.; Manoj, M.K. Effect of welding speeds on microstructure and mechanical properties of dissimilar friction stir welding of AA7075 and AA5083 alloy. Mater. Today 2020, 27, 2713-2717. [CrossRef] 
21. Darvazi, A.R.; Iranmanesh, M. Thermal modeling of friction stir welding of stainless steel 304L. Int. J. Adv. Manuf. Technol. 2014, 75, 1299-1307. [CrossRef]

22. Chen, Y.H.; Ni, Q.; Ke, L.M. Interfacial properties of friction stir welded lap joints of Ti/ Al dissimilar alloys. Trans. Nonferrous Met. Soc. China 2012, 22, 299-304. [CrossRef]

23. Deng, Y.L.; Deng, S.H.; Ye, L.Y.; Lin, S. Effects of post-weld heat treatment on microstructures and mechanical properties of AA7204-T4 aluminum alloy FSW joint. J. Mater. Eng. 2020, 48, 131-138. 